\title{
Long-term follow-up in primary pulmonary hypertension
}

\author{
LUIS D. SUAREZ, ENRIQUE E. SCIANDRO, JUAN J. LLERA, AND \\ ALBINO M. PEROSIO \\ From the Section of Cardiology, Hospital de Clinicas fosé de San Martin, University of Buenos Aires, \\ Buenos Aires, Argentina
}

SUMMARY Two patients with severe primary pulmonary hypertension, who are alive 38 and 27 years after the onset of the disease, were closely followed by the authors for 24 years. No previous report of such a long course has been found. Despite pulmonary artery pressures at systemic level, effort syncope disappeared and there were long intervals without symptoms during which the 2 patients were able to take part in physical activity with minimal discomfort. Severe primary pulmonary hypertension should not always be considered a malignant disease.

In most cases of primary pulmonary hypertension the onset of symptoms is followed by death within a period of a few months up to 3 years (Wood, 1956). Effort syncope and uncontrollable acute or chronic heart failure are the most common causes of death (Fowler et al., 1966; Degeorges et al., 1970). In addition death may occur during, or shortly after, cardiac catheterisation (Schafer et al., 1956), or during very simple procedures such as the determination of the circulation time (Cutler et al., 1954). No effective treatment is yet available, and many therapeutic measures may even be dangerous (Inkley et al., 1955). As a consequence of all these features primary pulmonary hypertension has been considered a malignant disease. However, a careful review of available publications reveals several cases with a survival of 10 to 20 years (McCallum, 1931; Wood, 1956; Nielsen and Fabricius, 1961; Sleeper et al., 1962; Melmon and Braunwald, 1963; Fowler et al., 1966; Charters and Baker, 1970; Degeorges et al., 1970). Patients with an unusually long history, 20 to 29 years, were reported by Wagenvoort and Wagenvoort (1970). Recently, Trell (1973) described 2 patients whose disease lasted 27 and 40 years respectively, though both had only moderate degrees of pulmonary hypertension for most of the duration of their illnesses.

From March 1953 to the present, 24 cases of severe primary pulmonary hypertension have been studied by the authors at the Hospital de Clínicas

Received for publication 14 July 1978 of Buenos Aires. Two of them, who are alive 38 and 27 years after the onset of the disease, were closely followed up for 24 years. Both patients were included (cases 1 and 2) in a previous early series (Perosio et al., 1960). A description of the chief features of these unusual cases is the purpose of this report.

\section{Patients}

CASE 1

A 29-year-old woman was admitted to the Hospital de Clínicas in November 1954 because of fatigue and dyspnoea on exertion experienced during the past 14 years; since 1950 she had had 3 episodes of effort syncope. In addition, at the age of 17, symptoms of typical rheumatoid arthritis developed, and the patient was told that she had rheumatic valvular heart disease. During the previous 12 years she had been admitted several times to different hospitals with the same diagnoses. She gave no history suggestive of thromboembolism and there was no family history of heart disease.

Physical examination disclosed slight cyanosis of the lips and cheeks. Pronounced deformities of the rheumatoid arthritis type were present. The blood pressure was $115 / 75 \mathrm{mmHg}$. The jugular venous pulse revealed prominent $a$ waves. The cardiac impulse was powerful, sustained, and was maximal at the lower left sternal border. On auscultation an ejection click could be heard in the pulmonary area. A fourth heart sound was present. The second heart sound was closely split with a 


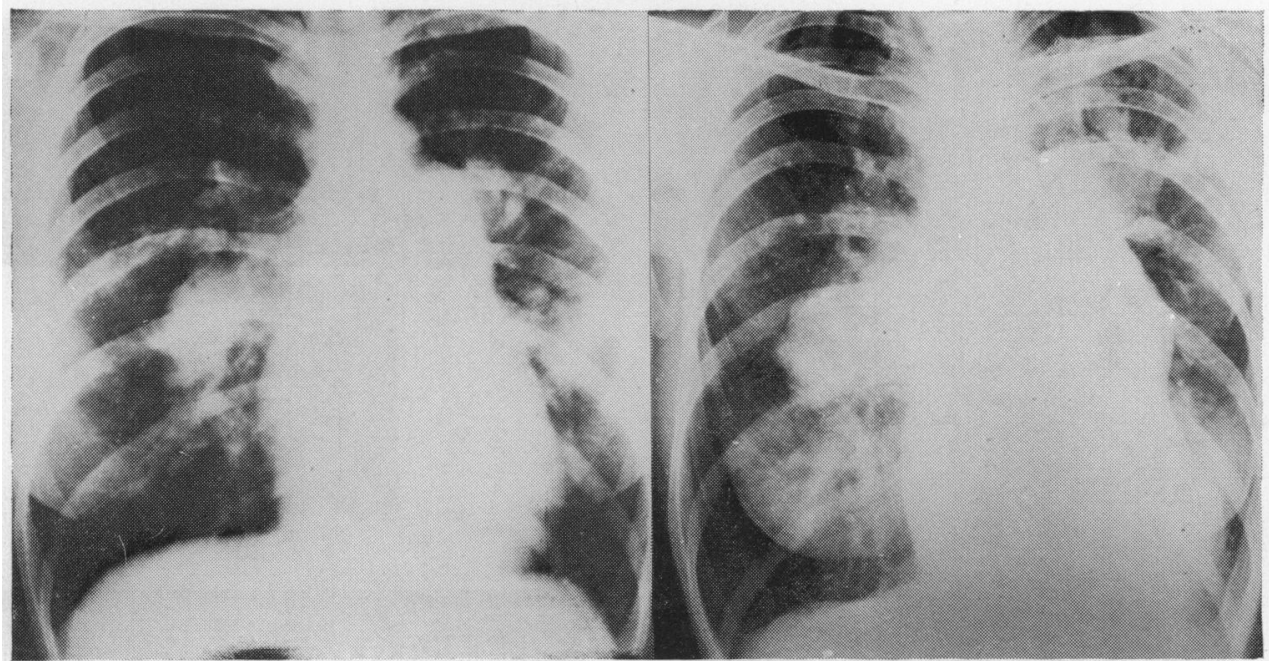

A

B

Fig. 1 Case 1. X-ray pictures of November $1954(A)$, and March $1978(B)$.

loud pulmonary component at the second left interspace, followed by an immediate decrescendo diastolic murmur of the Graham Steell type.

The chest $x$-ray film showed right ventricular enlargement, prominent main pulmonary segment, considerable dilatation of the two main branches of the pulmonary artery, and diminished peripheral pulmonary vascularity (Fig. 1A). The respiratory function tests and the values for alveolar $\mathrm{PO}_{2}$ and $\mathrm{PCO}_{2}$ were normal.

The electrocardiogram showed a mean QRS frontal axis of $+120^{\circ}$, tall $R$ waves in right and mid-praecordial leads with a $\mathrm{qR}$ pattern in V1, and negative $\mathrm{T}$ waves in II, III, aVF, and in all the praecordial leads (Fig. 2A). The vectorcardiogram (Grishman's cube system) showed clockwise inscription of the QRS loop in both the frontal and horizontal planes. The initial forces were directed to the left, and the body of the QRS loop was displaced anteriorly and rightward. Discordant $T$ loops were recorded (Fig. 3A).

A haemodynamic study showed the following: (1) there was no evidence of a left-to-right shunt, and the systemic arterial oxygen saturation was normal; (2) the pulmonary arterial and right ventricular pressures were at systemic level ; (3) pulmonary artery wedge pressure was normal; and (4) pulmonary resistance was much increased (Table). Right angiograms showed gross dilatation of the pulmonary trunk and its main branches, with lack of arborisation of the pulmonary vascular tree (Fig. 4). A few minutes after the cardiac catheterisation, the patient abruptly developed typical pulmonary oedema. The treatment was effective, but 15 minutes later the patient's blood pressure dropped precipitously and other signs of circulatory collapse followed. Plasma $(500 \mathrm{ml})$ and an infusion of $4 \mathrm{mg} /$ $1000 \mathrm{ml}$ of noradrenalin were administered. Six hours later the patient improved. She remained well and was discharged from hospital. No special treatment was instituted, except a sodium-free diet and digoxin $0.25 \mathrm{mg}$ daily.

From December 1954 to July 1961 the patient experienced 3 episodes of loss of consciousness during heavy exercise. But for the next 5 years she remained asymptomatic. Digoxin was then discontinued.

In August 1966, she presented with 2 haemoptyses with symptoms of right-sided heart failure. There were no symptoms to suggest venous thrombosis or pulmonary embolism. Two weeks later she improved steadily and from September 1966 to July 1969 was asymptomatic. Treatment was discontinued in November 1969.

In June 1971, the patient developed bacterial pneumonia and symptoms of right-sided heart failure recurred. The electrocardiogram was unchanged from the earlier admission. Chest $x$-ray film showed a typical pneumonic shadow in the upper left lung field. Treatment with penicillin, streptomycin, digoxin, frusemide, and oxygen was effective.

An echocardiogram was first recorded in June 1973 and showed right ventricular enlargement with normal left atrial size. The mitral valve was normal (Fig. 5). 


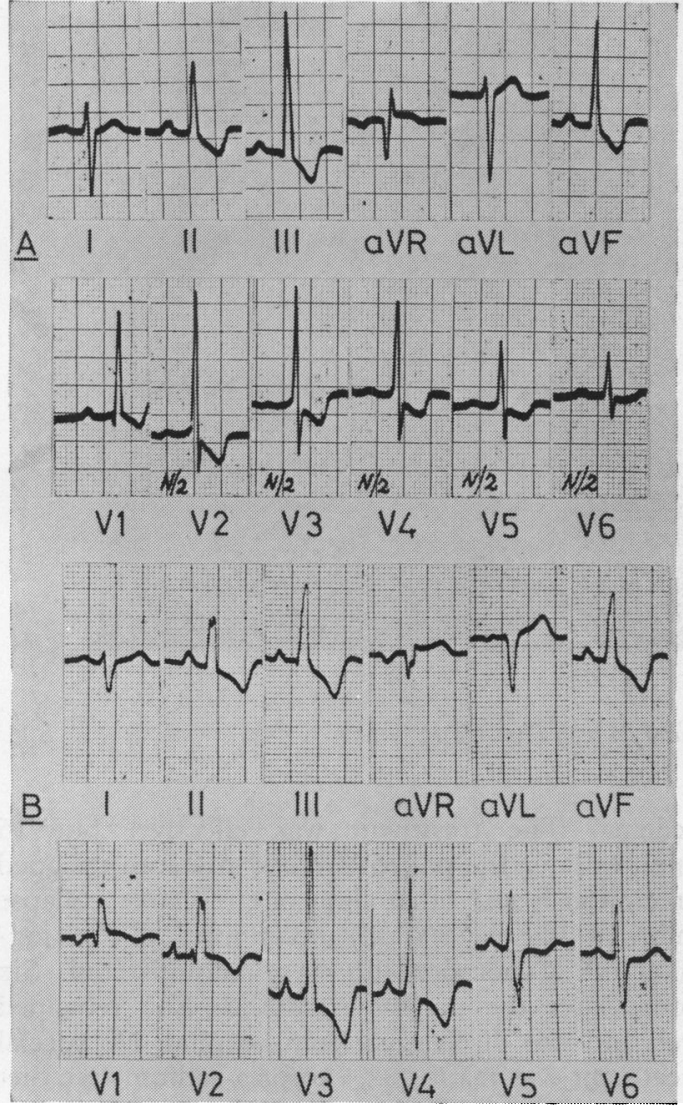

Fig. 2 Case 1. Electrocardiograms recorded in November $1954(A)$, and in March $1978(B)$. Calibration, $1 \mathrm{~cm}=$ $1 \mathrm{mV}$, except in $V 2$ to $V 6$ of the tracing $A$ in which $0.5 \mathrm{~cm}=1 \mathrm{mV}$.

From 1973 to the present (June 1978) the patient has remained well and she can do all her house work without discomfort. On examination in March 1978 the physical findings were substantially the same as those in 1954 (Fig. 6). The electrocardiogram showed the following changes: (1) a greater duration of the QRS complexes, (2) signs of right atrial hypertrophy, and (3) positive $T$ waves in left

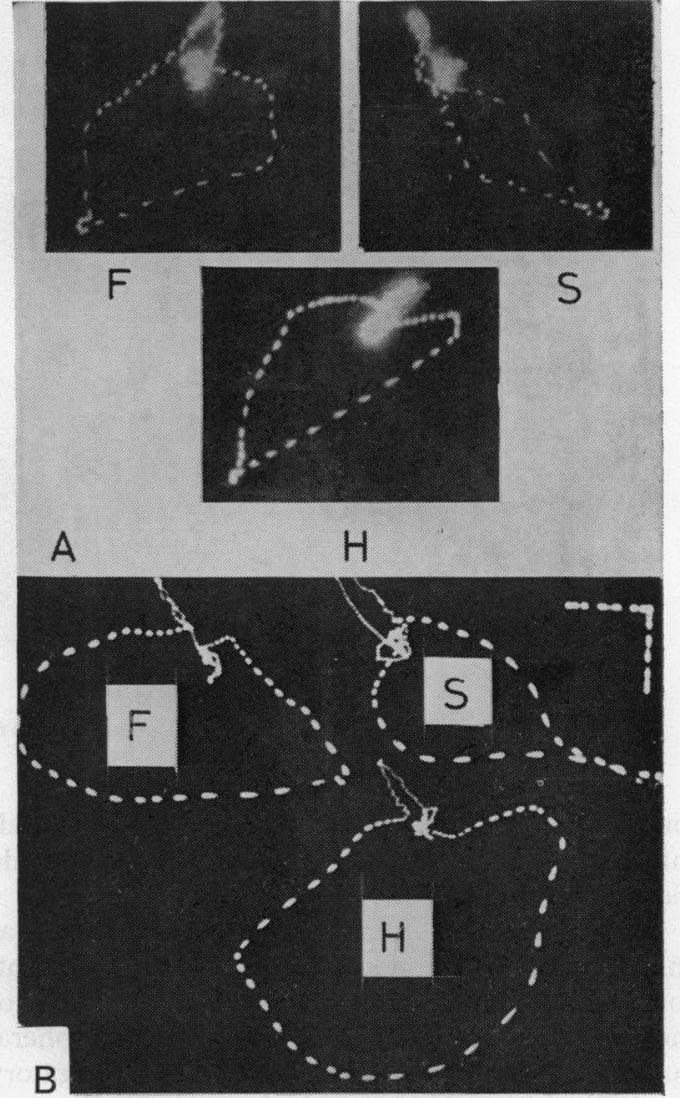

Fig. 3 Case 1. Vectorcardiograms recorded in November 1954 with the Grishman's cube system $(A)$, and in March 1978 with the Frank system $(B)$. Calibration signal, $0 \cdot 5$ $m V$.

praecordial leads (Fig. 2B). The vectorcardiogram recorded with the Frank system revealed a rightward shift of the T loop in both the horizontal and frontal planes (Fig. 3B). The chest $x$-ray film showed an increase in the size of the cardiovascular shadow, and increased prominence of the pulmonary trunk and dilatation of its main branches (Fig. 1B).

Table Haemodynamic data

\begin{tabular}{|c|c|c|c|c|c|c|c|}
\hline Case no. & $\begin{array}{l}\text { Right } \\
\text { atrium }\end{array}$ & $\begin{array}{l}\text { Right } \\
\text { ventricle }\end{array}$ & $\begin{array}{l}\text { Pulmonary } \\
\text { artery }\end{array}$ & $\begin{array}{l}\text { Pulmonary } \\
\text { artery wedge }\end{array}$ & $\begin{array}{l}\text { Brachial } \\
\text { artery }\end{array}$ & $\begin{array}{l}\text { Total pulmonary } \\
\text { resistance } \\
\left(\text { dynes } \mathrm{cm} \mathrm{s}^{-5}\right)\end{array}$ & $\begin{array}{l}\text { Cardiac index } \\
\left.\text { (l/min per } m^{2}\right)\end{array}$ \\
\hline
\end{tabular}

S/D-M, systolic/diastolic-mean. 


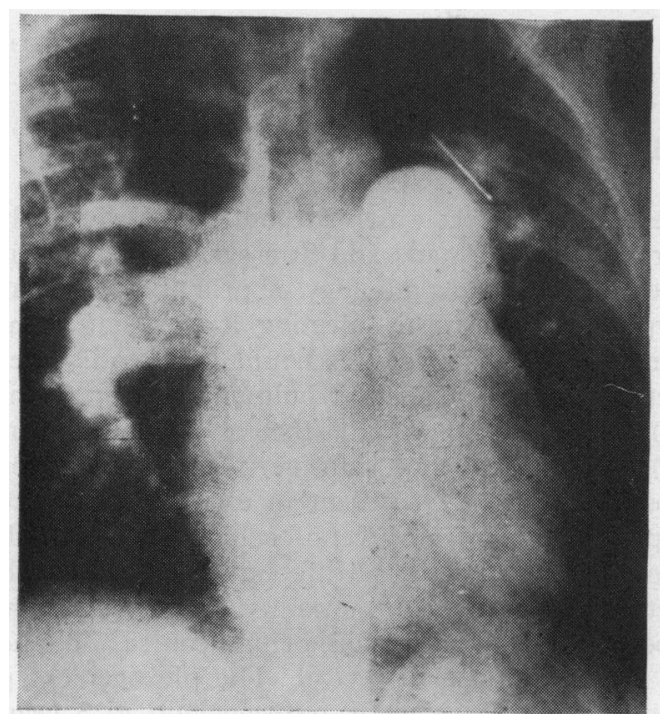

Fig. 4 Case 1. Right angiogram obtained in November 1954 showing gross dilatation of the pulmonary trunk and its main branches with lack of arborisation of the pulmonary vascular tree.

\section{CASE 2}

A 6-year-old boy was first seen in July 1954 because of fatigue, dyspnoea on exertion, and effort syncope. These symptoms had begun by the time he was 3 years of age. During the previous year he had had 7 syncopal attacks. Slight cyanosis on exertion was noted by his mother.

On examination the blood pressure was $100 / 70$ $\mathrm{mmHg}$. The cardiac impulse was prominent under the xiphoid process. On auscultation a pulmonary ejection click and a closely split second heart sound with a loud pulmonary component were heard in the pulmonary area. In addition a grade $3 / 6$ pansystolic murmur could be heard at the tricuspid area, suggesting functional tricuspid regurgitation.

The chest $x$-ray film showed conspicuous dilatation of the main pulmonary segment, enlargement of the right ventricle, and increased hilar vessels in contrast with decreased peripheral pulmonary vascularity (Fig. 7A). The pulmonary function tests were normal.

The electrocardiogram revealed a mean QRS frontal axis of $+150^{\circ}$, prominent $R$ waves from V4R to V2, and positive $T$ waves in all the praecordial leads (Fig. 8A). The vectorcardiogram showed the typical pattern of right ventricular hypertrophy type A.

The haemodynamic findings were similar to those in case 1 (Table). Right angiograms showed considerable dilatation of the pulmonary artery,

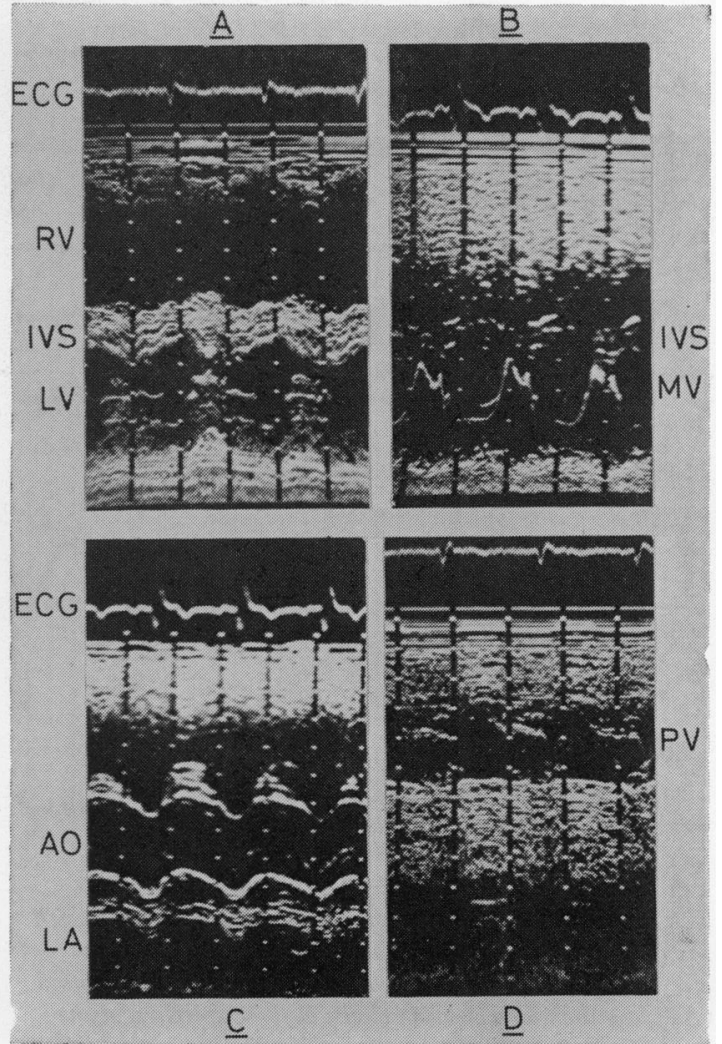

Fig. 5 Case 1. Echocardiogram recorded in fune 1973 showing dilatation of the right ventricle $(A)$, normal mitral valve $(B)$, normal left atrial size $(C)$, absence of the a wave and mid-systolic closure of the pulmonary valve (D). IVS, interventricular septum; $R V$, right ventricle; $L V$, left ventricle; $M V$, mitral valve; $A O$, aorta; $L A$, left atrium; $P V$, pulmonary valve.

with reduced pulmonary vascularity and no evidence of intra or extracardiac shunts.

During the first 4 years of follow-up, tolazoline, aminophylline, and digoxin were administered. In spite of this treatment he experienced several episodes of effort syncope. Nevertheless, he looked healthy when examined in 1958. The auscultatory, radiological, and electrocardiographic findings were similar to those recorded in 1954.

From 1958 to 1963 the patient improved. He experienced slight dyspnoea on exertion but sometimes he could carry out physical activities without breathlessness. On examination in June 1964, slight venous congestion with prominent $a$ waves could be seen in the neck. At this time a grade 3/6 diastolic murmur was found in the pulmonary area and along the left sternal border.

Since 1964 there have been no further episodes 


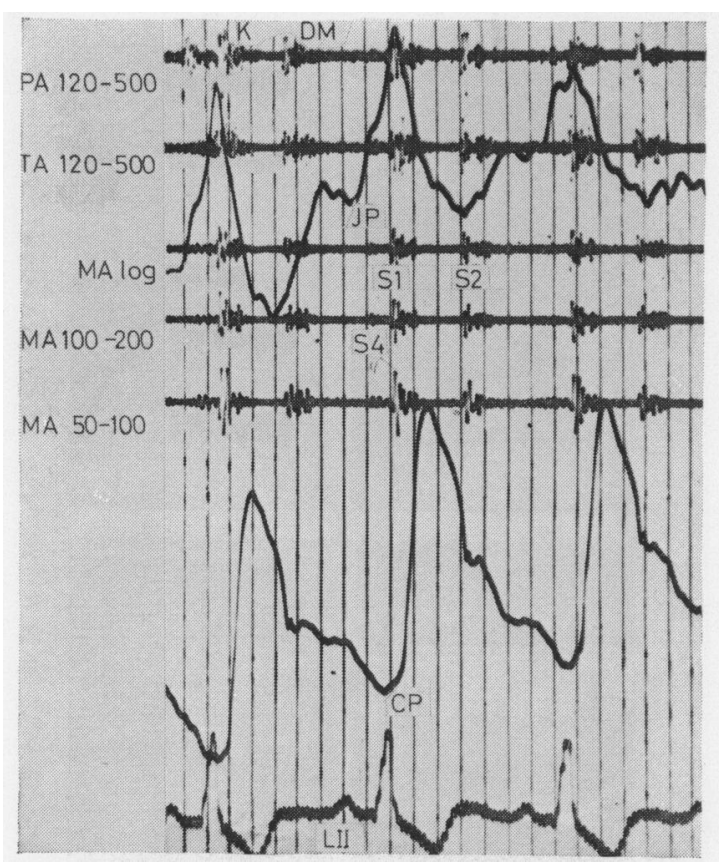

Fig. 6 Case 1. Logarithmic (Log), and filtered (120$500 \mathrm{~Hz}$ ) phonocardiograms, recorded simultaneously with the jugular pulse (fPP), the carotid pulse (CP), and the electrocardiogram (lead II), showing a fourth heart sound (S4), a pulmonary ejection click $(K)$, the splitting of the second heart sound $(S 2)$ with a loud pulmonary component, and the diastolic murmur of the Graham Steell type (DM). Note the giant a waves in the jugular venous pulse. Paper speed, $50 \mathrm{~mm} / \mathrm{s} . P A$, pulmonary area; $T A$, tricuspid area; $M A$, mitral area.

of effort syncope. Throughout the next 10 years there was an alternating course of asymptomatic periods and times when symptoms of moderate right-sided heart failure and low pulmonary output were present. The causes of these changes in the clinical status of the patient were not evident: sometimes it was thought that influenza or bronchitis was responsible.

A phonocardiogram recorded in September 1974 revealed no changes in the auscultatory findings. The echocardiogram showed similar features to those in case 1 .

During the last 3 years the patient has remained well. Physical findings are unchanged. The electrocardiogram shows an increase in $P$ wave voltage. Conversely the $\mathbf{R}$ waves in the right praecordial leads are smaller than those observed in 1954 (Fig. $8 \mathrm{~B})$. The chest $x$-ray film shows reduced cardiothoracic ratio, though there has been an increase in the dilatation of the main pulmonary segment with diminished peripheral pulmonary vascularity (Fig. 7B).

\section{Discussion}

Recently an effort was made by the World Health Organization (Hatano and Strasser, 1975) to clarify the aetiology and pathology of primary pulmonary hypertension. At this meeting it was stated that three pathological entities could be found. These entities are (1) plexogenic pulmonary arteriopathy, (2) recurrent pulmonary thromboembolism, and (3) pulmonary veno-occlusive disease. The prognosis seems to be different in each of these three types. The pulmonary veno-occlusive form has the more severe course, and life expectancy is usually between a few months and 2 years. The thromboembolic form has a more benign course and tends to have the longest survival. The plexogenic type lies between these, with a survival up to 3 years. Though our 2 patients have the clinical and radiological presentation of the last type (Hatano and Strasser, 1975), definitive diagnosis is not possible without histological examination obtained either by biopsy or necropsy (Edwards and Edwards, 1977).

From the clinical viewpoint the most sinister prognostic signs in all the reported cases have been recurrent effort syncope and progressive right-sided heart failure (Nielsen and Fabricius, 1961; Fowler et al., 1966; Degeorges et al., 1970; Nadas and Fyler, 1972). The first was present in our 2 patients and especially in case 2 . However, after a period of 9 to 12 years this symptom disappeared spontaneously. In the case reported by Charters and Baker (1970), effort syncope also remitted for long intervals, but then recurred and finally the patient died suddenly. Signs of right-sided heart failure were present in the 2 patients, frequently occurring after complicating events; they were easily managed with conventional treatment.

Electrocardiographic evidence of right ventricular hypertrophy is recorded in 100 per cent of cases (Degeorges et al., 1970) and is not useful in assessing prognosis. However, severe right atrial overload and arrhythmias are features which tend to occur in very ill patients and imply a poor prognosis (Delaye et al., 1970). The most recent electrocardiogram in case 1 showed increased QRS duration and increased signs of right atrial overload, though there was little change in the QRS loops in the vectorcardiograms. On the other hand, the recent electrocardiogram in case 2 suggested a lesser degree of right ventricular overload. There was similar regression of electrocardiographic changes in the patient reported by Bourdillon and Oakley 


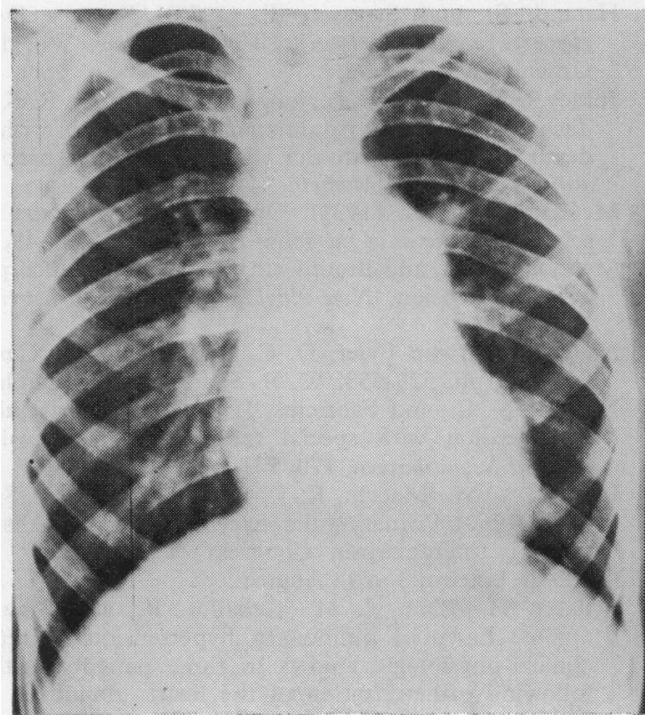

A

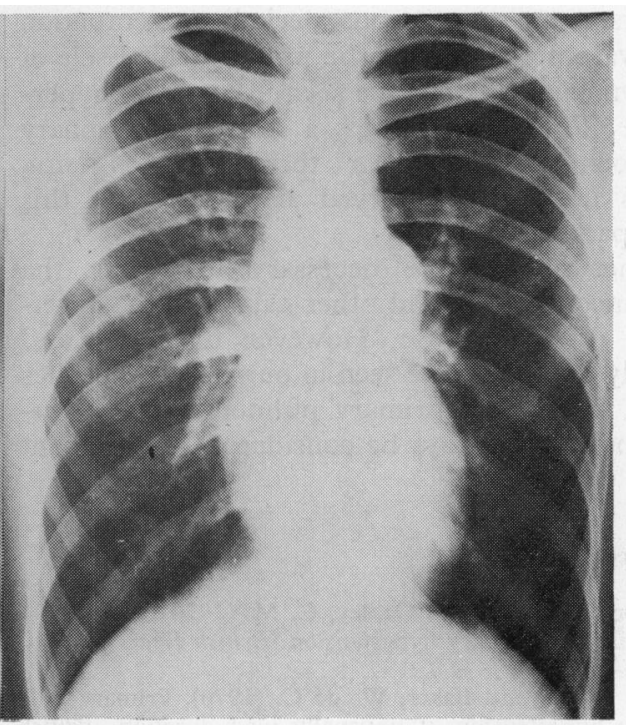

B

Fig. 7 Case 2. X-ray films of $f$ uly $1954(A)$, and March $1978(B)$.

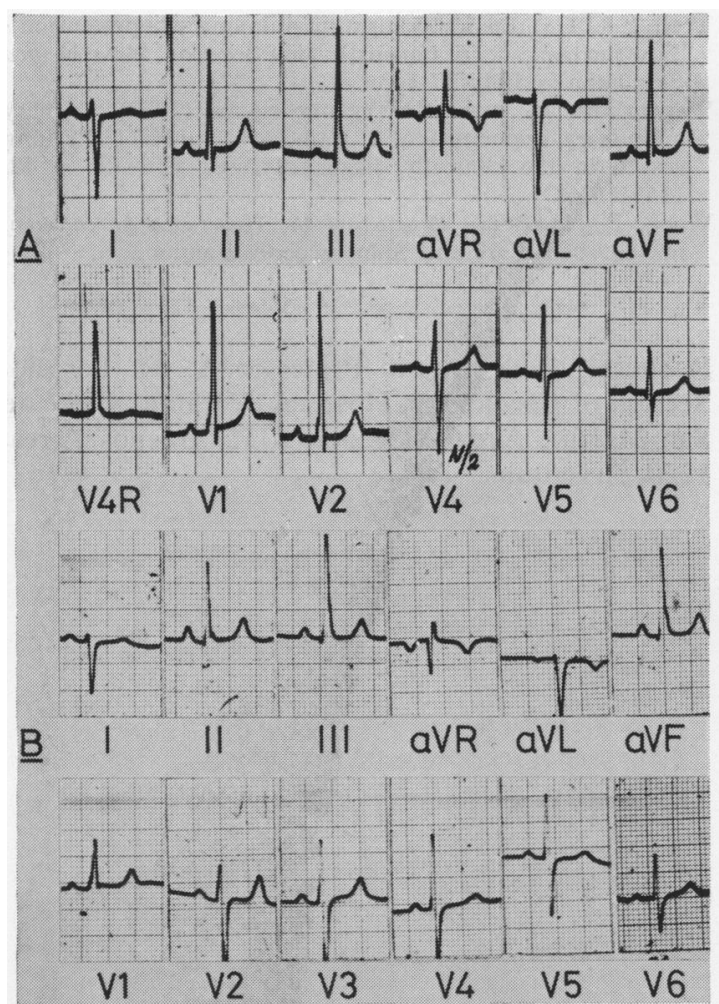

Fig. 8 Case 2. Electrocardiograms recorded in fuly 1954 $(A)$, and in March $1978(B)$. Calibration $1 \mathrm{~cm}=1 \mathrm{mV}$, except in $V 4$ of the tracing $A$ in which $1 \mathrm{~cm}=0.5 \mathrm{mV}$.
(1976), in whom there was clinical and radiological improvement with reduction in pulmonary hypertension. In our case 2, however, clinical evidence of right atrial and ventricular overload increased, and the regression of the electrocardiographic right ventricular hypertrophy was probably attributable to a change in the shape of the thorax with growth.

A poor correlation seems to exist between pulmonary arterial pressure or other haemodynamic data and survival (Degeorges et al., 1970). The long survival of our 2 cases supports this concept. However, most patients with severe pulmonary hypertension and low cardiac output follow a relentless downhill course. Few reported cases have had repeated haemodynamic studies (Sleeper et al., 1962; Farrar et al., 1961). Nielsen and Fabricius (1961) were able to repeat cardiac catheterisation in 5 cases: they found that pulmonary pressure increased considerably in 3 but remained unchanged in the other 2. Stabilisation of the haemodynamic abnormalities may explain the relatively benign course in our patients who did not consent to further invasive studies. A similar stable condition over several years in a case with mild pulmonary hypertension was recorded by Trell (1973).

It is interesting to note that in the long course of our 2 patients prolonged intervals without symptoms occurred in spite of discontinuing treatment. Sometimes purulent bronchitis or pneumonia with possible subsequent anoxia seemed to be a likely explanation for relapse, but frequently no cause could be found. Two possibilities were considered. 
The first was spontaneous periodic accentuation of the vasomotor tone of the pulmonary vessels of unknown origin, as may be seen in systemic hypertension. The second was a minor pulmonary thromboembolic event or thrombosis in situ, findings frequently observed at necropsy in this type of patient.

Further studies are necessary to clarify the importance of these and other causes in the development of the disease. However the long and relatively benign course seen in our patients implies at least that severe primary pulmonary hypertension should not always be considered a malignant disease.

\section{References}

Bourdillon, P. D. V., and Oakley, C. M. (1976). Regression of primary pulmonary hypertension. British Heart fournal, 38, 264-270.

Charters, A. D., and Baker, W. de C. (1970). Primary pulmonary hypertension of unusually long duration. British Heart fournal, 32, 130-133.

Cutler, J. G., Nadas, A. S., Goodale, W. T., Hickler, R. B., and Rudolph, A. M. (1954). Pulmonary arterial hypertension with markedly increased pulmonary resistance. American fournal of Medicine, 17, 485-498.

Degeorges, M., Herreman, F., and Fagot, D. (1970). L'hypertension artérielle pulmonaire primitive. Coeur et Médecine Interne, 9, 283-299.

Delaye, J., Delahaye, J. P., Age, C., and Gonin, A. (1970) Les formes familiales de l'hypertension artérielle pulmonaire primitive. In Actualités Cardiovasculaires Médico-chirurgicals, pp. 201-215, ed R. Froment, A. Gonin, and P. Michaud. Masson et Cie, Paris.

Edwards, W. D., and Edwards, J. E. (1977). Clinical primary pulmonary hypertension. Three pathologic types. Circulation, 56, 884-888.

Farrar, J. F., Reye, R. D. K., and Stuckey, D. (1961). Primary pulmonary hypertension in childhood. British Heart Fournal, 23, 605-615.

Fowler, N. O., Black-Schaffer, B., Scott, R. C., and Gueron, M. (1966). Idiopathic and thromboembolic pulmonary hypertension. American fournal of Medicine, 40, 331-345.
Hatano, S., and Strasser, T. (1975). Primary Pulmonary Hypertension. Report on a WHO Meeting. World Health Organization, Geneva.

Inkley, S. R., Gillespie, L., jun, and Funkhouser, R. K. (1955). Two cases of primary pulmonary hypertension with sudden death associated with the administration of barbiturates. Annals of Internal Medicine, 43, 396-406.

McCallum, W. C. (1931). Obliterative pulmonary arteriosclerosis. Bulletin of the fohns Hopkins Hospital, 49, 37-48.

Melmon, K. L., and Braunwald, E. (1963). Familial pulmonary hypertension. New England fournal of Medicine, 269, 770-775.

Nadas, A. S., and Fyler, D. C. (1972). Pediatric Cardiology, 3rd edn, pp. 529-533. W. B. Saunders, Philadelphia.

Nielsen, N. C., and Fabricius, J. (1961). Primary pulmonary hypertension with special reference to prognosis. Acta Medica Scandinavica, 170, 731-741.

Perosio, A. M., Macchi, R. J., Suárez, L. D., and Sciandro, E. E. (1960). Primary pulmonary hypertension. Abstracts of the VI Interamerican Congress of Cardiology, p. 146. Río de Janeiro, 8 to 13 August.

Schafer, H., Blain, J. M., Ceballos, R., and Bing, R. J. (1956). Essential pulmonary hypertension: a report of clinical-physiologic studies in three patients, with death following catheterization of the heart. Annals of Internal Medicine, 44, 505-523.

Sleeper, J. C., Orgain, E. S., and McIntosh, H. D. (1962) Primary pulmonary hypertension. Review of clinical features and pathologic physiology with a report of pulmonary hemodinamics derived from repeated catheterization. Circulation, 26, 1358-1369.

Trell, E. (1973). Benign, idiopathic pulmonary hypertension ? Two further cases of unusually long duration. Acta Medica Scandinavica, 193, 137-143.

Wagenvoort, C. A., and Wagenvoort, N. (1970). Primary pulmonary hypertension. A pathologic study of the lung vessels in 156 clinically diagnosed cases. Circulation, 42 , 1163-1184.

Wood, P. H. (1956). Diseases of the Heart and Circulation, pp. 839-848. Eyre and Spottiswoode, London.

Requests for reprints to Professor A. M. Perosio, Section of Cardiology, Hospital de Clínicas José de San Martín, Avda. Córdoba 2351, Buenos Aires, 1220, Argentina. 